\section{Goudimel, Claude}

Geb. ca. 1514 in Besançon;

gest. 28.(?) 8.1572 in Lyon

G.s Schaffen ist mit den politischen Verhältnissen, den Religionskämpfen in Frankreich in der zweiten Hälfte des 16. Jahrhunderts, eng verbunden. Der größte Teil seines Euvres besteht aus Vertonungen von Psalmtexten des Hugenottenpsalters. Der Dichter Clément Marot, der wegen seiner papstfeindlichen Haltung vom Hofe Franz I. fliehen mußte, hatte Psalmtexte in französische Verse übertragen - zunächst auf beliebte Chansonmelodien, die von Calvin 1539 unter Hinzufügung eigener Dichtungen in einem Gesangbuch gedruckt wurden. 1562 erschien der vollständige Genfer Psalter mit 150 gereimten Psalmtexten von Marot und Téodore de Bèze, dem Nachfolger Calvins in Genf, mit 125 Melodien. G. hat die Psalmtexte in drei verschiedenen Versionen mehrstimmig gesetzt, die von einer sehr einfachen bis zu einer äußerst kunstvollen Kompositionsweise reichen.

Eine einfache Fassung wurde 1564 veröffentlicht (Nachdruck 1565). Ebenfalls 1564 (Nachdruck 1565: "Jacqui-Psalter «) folgte eine weitere Fassung mit allen 150 Psalmen, deren Sätze zumeist akkordisch in homorhythmischer Deklamation gehalten sind unter Verwendung der Psaltermelodie im Tenor. Die Stücke sind kurz, da ihnen nur der erste Psalmvers zugrunde liegt. 28 Stücke weisen einen polyphon aufgelockerten Satz auf. Die Vertonungen waren von G. für den Hausgebrauch bestimmt, wurden jedoch früh im reformatorischen Gottesdienst verwendet und fanden auch in anderen Ländern Verbreitung (die erste deutsche Ausgabe aus dem Jahre 1573 stammt von Ambrosius Lobwasser, der den Genfer Nachdruck von 1565 zur Grundlage seiner Ausgabe nahm). Eine erneute Vertonung der 150 Psalmen hat G. 1568 veröffentlicht. Sie enthält vierstimmige Stïcke in durchgehend polyphonem Satz und verwendet ebenfalls für alle Sätze die Psaltermelodie, die fast immer in der Oberstimme liegt, ein Brauch, den G. wahrscheinlich als erster einführte. Eine Anzahl Sätze aus der Sammlung von 1564-1565 wurde wiederum übernommen.

Musikalisch am interessantesten sind freilich die Psalmen in Motettenform. Sie wurden zwischen 1551 und 1566 in acht Büchern publiziert und enthalten insgesamt 67 Kompositionen. Nur ein Teil der Vertonungen basiert auf der hugenottischen Psaltermelodie und ein weiterer Teil macht von den entsprechenden Melodien freien $\mathrm{Ge}$ brauch, während sie im sechsten bis achten Buch durchgehend verwendet werden. Im Unterschied zu den beiden Versionen der 150 Psalmen zeichnen sich die Kompositionen hier durch extreme Länge aus, indem alle Verse eines Psalms vertont werden. Die Stücke sind in Abschnitte untergliedert, die jeweils mehrere Psalmstrophen enthalten können. Besonders die vielstrophigen Psalmvertonungen demonstrieren G.s Kunst der Variation. Die Stimmenanzahl von drei bis zu sechs Stimmen dient sowohl der Differenzierung der Abschnitte als auch der Steigerung: Besonders bemerkenswert ist das letzte Stück im siebten Buch Je t'aymeray en toute obeissance, dessen Schlußabschnitt die Achtstimmigkeit erreicht; Variationsreichtum zeigt sich zudem in der motivischen Gestaltung und in der Satztechnik. In dem weitgehend polyphonen Satz werden homophone Partien meist in textausdeutender Funktion eingesprengt, Durchimitation wechselt mit freierer Stimmbehandlung, Partien mit langmensuriertem cantus firmus und solche mit gleichrangigen Stimmen folgen aufeinander. G. hätte wohl weitere Bücher folgen lassen und auch die verbleibenden Psalmen in Motettenform komponiert, wenn er nicht Opfer der Glaubenskämpfe geworden wäre.

Neben seinen Psalmvertonungen, verschiedenen lateinischen Motetten, einem Magnificat und fünf sehr kurzen und einfachen Messen im französischen Stil hat sich G. auch der weltlichen Musik gewidmet. Seine Oden auf Texte von Horaz sind zwar verloren, seine Chansons (69 sind erhalten) auf Gedichte der berühmtesten Dichter wie Pierre Ronsard, Philippe Desportes oder Margarete von Navarra weisen ihn auch als gewandten Chansonkomponisten aus. Die polyphon aufgelockerte Satzweise entspricht derjenigen der zweiten Version der Psalmvertonungen, wobei jedoch textausdeutende Momente eine größere Rolle spielen.

Noten: Cl. G. Euvres complètes, hrsg. von P. Pidoux u. a., Institute of Medieval Music, Gesamtausgaben III, Brooklyn 1967-83.

Literatur: LaWry, E. M.: The Psalm Motets of Cl.G., Diss. N.Y. University 1954. Egan-Buffet, M.: Les Chansons de Cl.G. Analyses modales et stylistiques, Ottawa 1992 [mit Verz. der Chansons].

Elisabeth Schmierer 